\title{
A violência e o poder da(s) palavra(s): A religião cristã e as mulheres
}

The Violence and Power of the Word/Words: The Christian Religion and Women La violence et le pouvoir de la (des) parole (s) : la religion chrétienne et les femmes

\section{Teresa Martinho Toldy}

\section{(2) OpenEdition}

\section{Journals}

\section{Edição electrónica}

URL: http://journals.openedition.org/rccs/3761

DOI: $10.4000 /$ rccs.3761

ISSN: 2182-7435

\section{Editora}

Centro de Estudos Sociais da Universidade de Coimbra

Edição impressa

Data de publição: 1 Junho 2010

Paginação: 171-183

ISSN: 0254-1106

\section{Refêrencia eletrónica}

Teresa Martinho Toldy, «A violência e o poder da(s) palavra(s): A religião cristã e as mulheres »,

Revista Crítica de Ciências Sociais [Online], 89 | 2010, colocado online no dia 01 outubro 2012, criado a 20 abril 2019. URL : http://journals.openedition.org/rccs/3761 ; DOI : 10.4000/rccs.3761 


\section{A violência e o poder da(s) palavra(s): A religião cristã e as mulheres}

Falar-se-á aqui da violência da(s) palavra(s). Das formas como as palavras foram e são utilizadas para legitimar a violência patriarcal sobre as mulheres. Falar-se-á, em concreto, da forma como as palavras da Bíblia foram e são utilizadas para subalternizar as mulheres. Portanto, falaremos de discursos de poder. Mas também da possibilidade de outros discursos, de formas de empowerment "subalternas", a partir dos "sem-poder". Neste segundo aspecto, dar-se-á particularmente relevância ao pensamento e obra da teóloga feminista Elisabeth Schüssler Fiorenza.

Palavras-chave: antropologia teológica; hermenêutica feminista; mulheres; religião cristã; teologia feminista.

\section{Violência e cânone}

Mary Grey, num texto sobre a relação entre religião e violência contra as mulheres (1997: 504), afirma o seguinte:

É necessário ver ou considerar como uma das causas da violência na família o facto de todas as religiões apresentarem as mulheres na escritura e na tradição como se não fossem sujeitos humanos completos, mas apenas sujeitos subordinados, enquanto propriedade dos seus maridos ou pais. As mulheres, enquanto propriedade dos homens, ficam indefesas face aos maus-tratos ou face a assassinatos relacionados com os dotes.

\section{E acrescenta:}

Embora as Igrejas e comunidades de crentes lutem com sinceridade contra a pobreza, o facto de as mesmas se recusarem a evidenciar a ligação existente entre as suas autoridades masculinas e o abuso de poder, assim como a violência contra mulheres e crianças, constitui um erro crasso. Além disso, a religião também oculta a 
sua responsabilidade no facto de as mulheres serem condicionadas a aceitar normas culturais que sancionam positivamente a violência. ${ }^{1}$

Elisabeth Schüssler Fiorenza chama a atenção para aquilo que ela considera ser a produção de uma ideologia religiosa baseada numa dominação masculina estrutural, isto é, política, de raça e de classe, que se traduz numa opressão global, isto é, num sistema kyriocêntrico, numa pirâmide de múltiplas opressões (1992: 114 ss.). Os textos bíblicos e as interpretações a que os mesmos foram sujeitos ao longo dos séculos constituíram uma peça importante do "discurso kyriárquico", para utilizar a expressão de Schüssler Fiorenza (1994: 100). Parece existir, realmente, um "cânone da opressão", que, nas religiões monoteístas, passa pelos livros sagrados e pelas suas interpretações e reinterpretações por parte das instâncias emissoras dos discursos oficiais (sempre masculinas!). O patriarcado não é compreendido nos termos de um sistema sexual binário, mas sim como uma complexa estrutura piramidal de domínio político e de subordinação, estratificada segundo taxonomias de sexo, raça, classe, religião e cultura.

Mas o cânone também pode ser lido numa outra perspectiva. É sabido que a libertação dos véus impostos pela tradição androcêntrica cristã conheceu um momento decisivo nas lutas pela abolição da escravatura, por exemplo. Ora o cânone bíblico desempenhou um papel decisivo nessa luta, ainda que se possa dizer, simultaneamente, que a força mais poderosa na manutenção da submissão da mulher era a religião. As memórias inspiradoras desse percurso de libertação desempenham um papel significativo na reconstrução da identidade feminina, mais, são mesmo invocadas como "texto sagrado".

Contudo, a reconstrução do cânone religioso da libertação põe o dedo na ferida da utilização do mesmo para legitimar uma ordem social imperialista e colonialista. Um exemplo disto é a referência de Howard Thurman, numa entrevista concedida a Mary Goodwin (1973), à reacção da sua avó escrava perante a forma como a Bíblia também foi utilizada para legitimar a escravatura:

\footnotetext{
1 "Dass alle Religionen in Schrift und Tradition Frauen so darstellen, als seien sie keine vollen, menschlichen Subjekte, sondern als Eigentum ihrer Ehemänner oder Väter nur untergeordnete Subjekte, muss al seine der Ursachen für Gewalt in der Familie gesehen warden. Frauen als Eigentum von Männern sind wehrlos gegenüber Misshandlungen und Mitgiftmord. Obwohl Kirchen und Glaubensgemeinschaften aufrichtig gegen der Armut kämpfen, ist das Versäumnis der Kirchen, die Verbindung von ihren männlichen Autoritäten mit dem Missbrauch von Macht und der Gewalt gegen Frauen und Kinder aufzuzeigen, ein eklatanter Fehler. Ebenso verschweigt die Religion, dass sie dafür verantworlich ist, dass Frauen konditioniert werden, kulturelle Normen hinzunehemen, die Gewalt sanktionieren.” As traduções são da autora.
} 
Às vezes, era permitido ao ministro do fazendeiro fazer um serviço litúrgico para os escravos, e ele pregava sempre o mesmo texto: 'Os escravos sejam obedientes aos seus senhores, pois isto é justo aos olhos do Senhor'. A minha avó dizia que tinha decidido naquele momento que, se alguma vez aprendesse a ler ou se a liberdade alguma vez viesse, nunca leria aquele passo da Bíblia. ${ }^{2}$

Falemos, pois, destas diferentes leituras dos textos, melhor, de leituras centenárias, legitimadoras da exclusão da mulher, e de leituras baseadas em experiências de libertação. Falemos de comunidades de intérpretes, falemos de poder: de quem o tem e de quem o sofre... e falemos de textos e de olhares de empowerment sobre os mesmos...

\section{Interpretações canónicas e silenciamento das mulheres - a violência das palavras}

Seria longa a lista de textos bíblicos que descrevem actos de violência sobre mulheres. Mas tão ou mais relevantes do que os textos bíblicos que descrevem actos violentos sobre mulheres são os textos que foram utilizados ao longo dos séculos (e continuam a ser) para legitimar o silenciamento (frequentemente violento) das mulheres, invocando a sua pretensa inferioridade em relação ao homem, inferioridade essa estabelecida pela própria criação, portanto "natural", já que não pode ser "o corpo" - a mulher a comandar "a cabeça" - o homem. O que está em causa é a hierarquização, inspirada na $1^{a}$ Carta de S. Paulo aos Coríntios $(11,3)$, onde se diz que "a cabeça de todo o homem é Cristo, a cabeça da mulher é o homem, e a cabeça de Cristo é Deus”.

Está criada aquela que será a matriz da exclusão das mulheres. De facto, ela resulta de uma teologia que foi desenvolvendo progressivamente toda uma reflexão antropológica centrada na temática da imagem e semelhança com Deus e do pecado original. Esta contribuiu decisivamente para uma visão da mulher como ser inferior e como tentadora, à semelhança de Eva. Associada a uma biologia e estratificação social aristotélicas, esta cosmovisão "empurrou" a maioria das mulheres para o domínio do privado, do lar, e para os papéis sociais relacionados com ele, universo único onde seria possível manter o seu espírito e o seu corpo "inferiores e pecaminosos" resguardados da perdição (para si e para os outros).

\footnotetext{
2 "Sometimes the plantation owner's minister would be permitted to hold a religious service for the slaves, and he always preached from the same text: 'Slaves, be obedient to your masters, for this is right in the Lord.' My grandmother said that she made up her mind then and there that if she ever learned to read or if freedom ever came she would never read that part of the Bible."
} 
Debrucemo-nos, então, um pouco mais sobre a reflexão teológica mencionada, começando, precisamente, pela figura de Eva. No século XI, Geoffroy de Vendôme escrevia o seguinte, referindo-se à mulher:

Esse sexo envenenou o nosso primeiro pai, que era também o seu marido e o seu pai, decapitou João Baptista, entregou o corajoso Sansão à morte. De certa maneira, também matou o Salvador, porque, se a sua falta não o tivesse exigido, o nosso Salvador não precisava de ter morrido. Maldito seja esse sexo no qual não existe nem temor, nem bondade, nem amizade e que deve ser mais temido quando é amado do que quando é odiado. (apud Dalarun, 1991: 35) ${ }^{3}$

A primeira mulher de que se fala aqui é Eva. Ao longo da Idade Média ela terá um peso desmedido no discurso teológico, moral e pastoral acerca das mulheres. Porém, a interpretação desfavorável à mulher dos textos de Génesis 3 não se inicia na Idade Média. Ela é herdeira da própria literatura patrística, onde a mulher (= Eva) já é identificada com o pecado original, com a tentadora do homem, a culpada da sua queda. Tradicionalmente, o seu papel no pecado original é considerado como o mais grave, como afirma Tertuliano:

Não sabes que és Eva, tu também? A sentença de Deus para este sexo continua a estar plenamente em vigor, portanto o seu pecado também continua a subsistir. Tu és a porta do Diabo, tu consentiste na sua árvore, tu foste a primeira a abandonar a lei divina. (apud Dalarun, 1991: 35) ${ }^{4}$

Nove séculos mais tarde, Geoffroy de Vendôme chega à mesma conclusão, depois de ter estendido a culpa da mulher à responsabilidade pela negação de Pedro (através da criada referida no relato evangélico):

Por isso, este sexo, cumprindo o seu ofício, à maneira de uma serva porteira, exclui da vida todos aqueles que seduz, como excluiu Pedro de Cristo, ou inclui-os na morte, como fez com Adão, no Paraíso. (apud Dalarun, 1991:36)5

\footnotetext{
3 "Ce sexe a empoisonné notre premier parent, qui était aussi son mari et son père, il a étranglé Jean-Baptiste, livré le très courageux Samson à la mort. D'une certaine manière aussi, il a tué le Sauveur, car si sa faute ne l'avait pas exigé, notre Sauveur n'aurait pas eu besoin de mourir. Malheur à ce sexe en qui n'est ni crainte, ni bonté, ni amitié et qui est plus à redouter lorsqu'il est aimé que lorsqu'il est hai."

4 “Ne sais-tu pas que tu es Ève toi aussi? La sentence de Dieu a encore aujourd'hui toute vigueur sur ce sexe, il faut donc bien que sa faute subsiste aussi. Tu es la porte du Diable, tu as consenti à son arbre, tu as la première déserté la loi divine."

5 "C'est pourquoi ce sexe, remplissant son office à la manière d'une servante portière, tous ceux qu'il séduit, soit il les exclut de la vie comme Pierre du Christ, soit il les inclut dans la mort comme Adam au Paradis."
} 
Os avisos do clero para que os seus membros se afastem das mulheres chegam ao ponto de a referir como "raiz do mal e de todos os vícios". Marbode, bispo de Rennes, escreveu, por volta de 1098, um texto onde identifica femina com meretrix, descrevendo-a como "uma cabeça de leão, uma cauda de dragão e, no meio, um fogo ardente" (apud Dalarun, 1991: 37). ${ }^{6}$ Ainda que este último texto represente um excesso, é comum a referência a Eva como "a porta da morte" (cf. S. Jerónimo, PL 22, col. 408; Sto. Agostinho, PL 38, col. 1108).

O tema de Eva (= todas as mulheres) como tentadora do homem poderá ter sido aquele que encontrou maior eco popular, ou que se prestou, inclusivamente na iconografia, a representações mais coloridas. Porém, começou a perfilar-se uma outra questão, cujo alcance teológico é tão ou mais importante do que o desta, a saber a pergunta acerca da imagem $e$ semelhança de Deus na mulher. Os dois expoentes máximos da reflexão sobre este problema foram, naturalmente, aqueles que constituem os expoentes máximos de toda a teologia ocidental em si mesma: Sto. Agostinho e S. Tomás de Aquino. ${ }^{7}$

A antropologia teológica de que ambos são herdeiros contém representações tanto judaicas, como gregas. O ser humano, criado à imagem e semelhança de Deus, é definido através de conceitos provenientes do dualismo platónico entre corpo (princípio passivo) e alma (princípio activo). A semelhança com Deus é tida como uma qualidade da alma espiritual que, uma vez não corpórea, assexuada, é igual, tanto no homem, como na mulher. Nesta perspectiva, ambos os sexos foram feitos para a união com Deus e para a salvação em Cristo.

Contudo, o homem será identificado no seu corpo com a sua alma assexuada (vir = homo; recorrendo a 1Cor 11,7, onde se diz que "o homem é a imagem e a glória de Deus; mas a mulher é a glória do homem”), enquanto a mulher será identificada através da distinção que nela existe entre o seu corpo (femina) e a sua alma (bomo). De facto, Sto. Agostinho pergunta-se porque não terá Deus criado "um auxiliar" masculino para Adão. E encontra resposta no papel da mulher na reprodução (cf. Sto. Agostinho, Gen ad litt. IX, 2,3; Civ. Dei, IXX, 24). O papel da mulher - tirada da costela do homem - é comparado ao da terra, que recebe a semente. A mulher é uma auxiliar passiva. Na geração da vida, Deus actua com a colaboração dos pais, na medida em que as "rationes seminales", através da potência do sémen masculino, se desenvolvem no tempo. Este sémen paterno é constituído por

\footnotetext{
6 "Une tête de lion, une queue de dragon et au milieu rien d'autre qu'un feu fervent."
}

${ }^{7}$ Ler-se-á com muito proveito a obra exemplar de Børresen (1968). 
duas partes: uma, invisível, é a "ratio seminalis", a outra, visível, é a própria matéria do sémen. Neste sémen masculino, já existem todas as partes da criança que irá nascer, ainda que de forma latente, isto é, na sua essência. A mãe contribui com a substância do corpo, na medida em que é nela que o embrião se desenvolverá. Portanto, o papel da mulher (corpo) é subordinado ao do homem (corpo+alma), uma vez que a mãe apenas contribui passivamente, enquanto a actividade se encontra apenas no pai (cf. Sto. Agostinho, cf. Gen ad litt. X, 20, 21; Civ. Dei XXII, 14).

A relação hierárquica existente entre Adão e Eva, na perspectiva de Sto. Agostinho, torna-se mais explícita ainda na sua teologia do pecado original. De facto, ele não considera Eva como primeira responsável pelo pecado. Apesar de ter sido ela a ser seduzida pela serpente, Adão é o grande responsável pelo pecado, uma vez que é ele o princípio activo da humanidade: recorde-se que, para Sto. Agostinho, a actividade sexual tem uma função instrumental na transmissão do pecado original (cf. Gen ad litt. XI, 27-42). Apesar de Cristo ter nascido de uma mulher, não possui pecado original, uma vez que ela apenas contribuiu com a substantia corporalis (cf. ibidem $X, 20$ ). O significado da hierarquia entre os sexos é extrapolado da ordem da criação para a ordem da salvação: enquanto homem perfeito, Cristo é o novo Adão, assume de forma exemplar o sexo masculino. Mas o seu plano salvífico também inclui o sexo feminino, uma vez que Ele nasceu de uma mulher. Ela é a nova Eva (cf. Sto. Agostinho, De fide et symbolo IV, 9; De diversis quaestionibus octoginta tribus 11; De agone christiano XXII, 24). Prosseguindo nesta tipologia, Sto. Agostinho chama à Igreja a nova Eva, a esposa de Cristo. Contudo, enquanto no par original - Adão e Eva - ambos eram ontologicamente iguais, o Filho de Deus é o novo Adão divino, enquanto a sua parceira feminina é apenas humana (cf. Sto. Agostinho, Nupt. et concup. II, 4.12).

S. Tomás de Aquino, cuja antropologia pressupõe o aristotelismo, define o ser humano distinguindo entre essência e acidentes. Segundo a essência, o homem e a mulher pertencem ambos ao género homo. A diferença sexual é acidental e funda-se na corporeidade (vir, femina) (cf. S. Tomás de Aquino, De ente et essentia II, 11-13; VI, 5). Enquanto princípio formal essencial (forma substantialis) do corpo humano, a alma (anima intellectiva) é igual em ambos os sexos (cf. Summa Theologica I, 75, 6, 1.4.6). Partindo da biologia aristotélica, S. Tomás define a mulher como um ser subdesenvolvido, ou um homem falhado (aliquid deficiens et occasionatum). De facto, é o sémen masculino que actua como "forma", enquanto o organismo feminino apenas contribui com a matéria. A função biológica da mulher é passiva e receptiva, portanto, a sua inferioridade orgânica determina a sua condição 
de ajudante do homem (referência ao texto do Génesis) (cf. S. Tomás de Aquino, ibidem, I, 92, 1; 99, 2).

S. Tomás associa a racionalidade superior ao homem. De facto, na sua perspectiva, existem dois tipos de capacidades da alma (potentiae animae): aquelas que actuam nos órgãos do corpo, e aquelas que não actuam como tal, como a inteligência e a vontade. Enquanto algo racional, isto é, não corpóreo, a alma humana não conhece distinções entre sexos, mas a alma da mulher actua em ligação com a sua feminilidade, portanto, no seu corpo inferior (cf. S. Tomás de Aquino, ibidem, I, 77, 5; 84, 7).

Apesar de $\mathrm{S}$. Tomás insistir na ideia de que a mulher é imagem e semelhança de Deus, distinguindo-se do homem apenas no seu corpo (cf. ibidem I, 93,6 ad 2), uma combinação entre Génesis $(1,27)$ e $1^{a}$ Carta de S. Paulo aos Coríntios $(11,7)$ leva-o a confirmar a exegese tradicional: a "imagem e semelhança com Deus" encontra-se de uma forma diferente no homem e na mulher. O homem é origem e fim da mulher, como Deus é origem e fim de toda a criação (cf. S. Tomás de Aquino, ibidem I, 93, 4 ad 1).

Ora, os documentos eclesiais, pelo menos, a partir de João XXIII (1958-1963), insistem na igual dignidade do homem e da mulher, baseada numa teologia da criação de ambos à imagem e semelhança de Deus, procurando, assim, ultrapassar definitivamente o modelo desigual, proveniente de uma intromissão da filosofia dualista na antropologia cristã.

Porém, nestes documentos verifica-se sempre a necessidade de acrescentar mais qualquer coisa para definir as mulheres: elas são mães e esposas, essencialmente. ${ }^{8}$ Deus assim o determinou, dadas as características biológicas com que as modelou. Estas ditam a sua psicologia e, inclusivamente, as suas tarefas sociais. ' (Note-se que, na teologia católica, não existe uma reflexão paralela sobre os homens como pais e esposos. Nem se caracteriza a sua dimensão social como uma "macro-paternidade"...).

A tendência, diria mais, a opção por uma reflexão antropológica que recorre constantemente a definições essencialistas da mulher, baseadas, fundamentalmente, na sua biologia, introduz uma contradição no discurso eclesial actual, que alterna entre uma antropologia genérica igualitária e uma antropologia específica de desigualdade. De facto, enquanto na teologia se afirmou programaticamente que a mulher é um homem falhado, como o fez $S$. Tomás de Aquino (cf. Summa Theologica I, 92, 1; 99, 2), não se insistia, evidentemente, numa antropologia que reconhecesse a igualdade entre os sexos. Por isso, a

\footnotetext{
${ }^{8}$ Cf., por exemplo, Mulieris dignitatem (1988).

9 Para uma análise mais detalhada da antropologia subjacente aos documentos oficiais da Igreja Católica sobre as mulheres, cf. Toldy (1998: 27-77).
} 
subalternização da mulher era coerente com o discurso antropológico. Agora, que a igualdade entre os sexos é defendida explicitamente, o discurso da Igreja entra em contradição consigo mesmo, ao insistir numa antropologia específica (isto é, uma reflexão concreta sobre a mulher) que fundamenta exclusões, nomeadamente, da vida pública - sempre que esta entrar em choque com a maternidade, "papel natural da mulher"10 - mas também de certas funções eclesiais.

\section{Para uma hermenêutica feminista da libertação ou a(s) palavra(s) entregue(s) às mulheres}

Haverá possibilidade de fazer outras leituras do cânone bíblico? A questão não é tanto saber se este é conciliável com o feminismo, mas, sobretudo, se é possível fazer uma leitura feminista dos documentos que mais afectam as mulheres, no Ocidente, isto é, da Bíblia. Estes textos serviram, ao longo da história, para legitimar a submissão das mulheres, mas foi igualmente com base neles que muitas delas reagiram contra esta submissão. A Bíblia constitui, portanto, uma "arma contra as mulheres" (1998), mas é também a sua "herança”. Na primeira obra de relevo - In Memory of Her - Schüssler Fiorenza declara que a herança das mulheres constitui a fonte do seu poder (1988a). ${ }^{11}$ Ora, a reconstrução da sua história bíblica, a recuperação da sua herança, constitui um dos passos decisivos para a sua libertação.

O critério último de interpretação e de adopção de um texto não se encontra no texto, mas sim na comunidade que o recebe. A comunidade a que Schüssler Fiorenza se refere é, precisamente, a comunidade das mulheres (1998a). Os textos que deixam transparecer uma luta contra o patriarcalismo constituem uma fonte, um reservatório no qual as mulheres encontram alimento para o processo da sua libertação (cf. ibidem). Contudo, é a experiência das mulheres e não os textos em si, que constitui a referência última da hermenêutica feminista. Esta procederá em vários passos.

O primeiro é o da hermenêutica da suspeita, que procede identificando o carácter e a dinâmica androcêntrico-patriarcal do texto e da sua interpretação (cf. Fiorenza, 1988a). O seu objectivo é retomar os fios perdidos do tecido da vida das mulheres, que os textos não retratam, antes, ocultam. Mas, esta revisão da história não é um processo tanto histórico-crítico, teológico ou filosófico, quanto um processo poético - o seu objectivo não é

\footnotetext{
${ }_{10}$ A este propósito, cf., por exemplo, Sacra Congregatio Pro Doctrina Fidei, (1974: 740); Paulo VI, (1971: 410); João Paulo II (1981: 627-628; 1989: 490 e 1165; 1992: 1061-1065; 1988: 1674-1677); Ratzinger (5/04/1991).

${ }^{11}$ A expressão provém originalmente de Judy Chicago, que a utiliza na sua obra The Dinner Party (1979).
} 
tanto a reconstituição quanto a reformulação retórica do lugar das mulheres nos textos, resultante da sua leitura e interpretação pelas próprias mulheres.

O segundo passo é constituído por uma hermenêutica da recordação (cf. Fiorenza, 1988a; 1998). Esta etapa procura ir mais longe, buscando as raízes profundas da vida e da luta das mulheres na igreja primitiva, portanto o contexto histórico do texto. Implica a identificação dos "interesses" ${ }^{12}$ subjacentes ao texto e o seu objectivo último é reconstruir a história do cristianismo primitivo como a história de homens e mulheres, como a memória e a herança da igreja das mulheres (cf. Fiorenza, 1992), de forma a poder legitimar a prática feminista actual numa tradição de libertação ininterrupta, apesar de silenciada pela versão triunfante.

O terceiro momento é o da avaliação ou proclamação (Fiorenza, 1992; 1988a). Depois de identificados os sinais concretos de androcentrismo revelados no texto, assim como a sua contextualização nas estruturas patriarcais e na luta das mulheres contra elas, procura-se avaliar o alcance do texto para a libertação das mulheres. Se o texto lhe era contrário, não deve ser considerado Palavra de Deus: uma hermenêutica da proclamação deve insistir para que os teólogos não revistam um texto patriarcal com autoridade divina, proclamando-o palavra de Deus (cf. Fiorenza, 1992). Não quer dizer que um texto deste tipo não possa ser utilizado pela igreja. Mas, nesse caso, deve ser lido criticamente, isto é, de forma a ficar claro o seu carácter e a sua função opressora. Este passo hermenêutico deve avaliar, igualmente, o contexto sociopolítico em que o texto bíblico é lido e recebido, actualmente. Resumindo, uma hermenêutica da avaliação e proclamação é aquela que pondera as implicações de um determinado texto para uma leitura feminista, para a pregação, o aconselhamento e o estudo individual da Bíblia (cf. Fiorenza, ibidem).

Por último, uma hermenêutica feminista crítica que procura reconstituir a história das mulheres, supõe, igualmente, uma hermenêutica da imaginação (cf. Fiorenza, 1988b). Esta procura fazer uma nova interpretação dos textos bíblicos, uma interpretação não-androcêntrica, criativa, de forma a recriar o texto. O contexto desta reinterpretação ou recriação é a igreja das mulberes, para a qual é transferida a autoridade da interpretação dos textos.

Numa das suas últimas obras, Fiorenza situa este discipulado de iguais no horizonte de uma hermenêutica do desejo (cf. 1998), isto é, que procura uma reconstrução dos textos, ou melhor, do contexto dos mesmos, que não

${ }^{12}$ Numa das suas últimas obras, Fiorenza chama a atenção para o facto de ter sido o feminismo político, inspirado, em parte em Habermas, a ter chamado a atenção para o carácter situado e "interessado" de todo o conhecimento, e não os estudos do género ou o feminismo pós-moderno (cf. 1998: 78). Este tema é, aliás, caro à filosofia feminista (cf. por exemplo Harding, 2004). 
está preocupada com a apresentação dos factos dos primórdios igualitários do cristianismo ou com a legitimação teológica das origens cristãs, mas sim com uma reconstituição dos primórdios do cristianismo que deram origem a visões cristãs e a movimentos igualitários, ao longo dos tempos. Sendo assim, o discipulado de iguais já é e ainda não é, porque:

não é possível "provar" metodologicamente que a bíblia defende a democracia igualitária e não a monarquia kyriarcal, uma vez que ambas as formas de organização social estão inscritas no universo sócio-simbólico dos textos bíblicos. [...] As ideias e crenças que temos hoje informam a maneira como lemos os textos do passado. (Fiorenza, 1998: 120) ${ }^{13}$

São os leitores que escolhem a forma como querem ler os textos, valorizando a vertente ou tendência dos mesmos que corresponde aos seus interesses.

Ora, segundo Fiorenza, para que uma hermenêutica do desejo não caia na armadilha de se tornar uma forma de leitura fundamentalista ou positivista, tem que ser acompanhada de uma hermenêutica da indeterminação (cf. Fiorenza, 1998: 121), isto é, uma hermenêutica que tenha em conta o facto de a possibilidade de interpretações plurais do texto apelar a uma hermenêutica de avaliação crítica, ou seja, uma interpretação que considere o texto como um lugar de luta pelo significado. O objectivo final é provar que a questão não é a da busca de uma interpretação "correcta", da interpretação exacta, mas sim da exploração dos paradigmas subjacentes a cada interpretação (cf. Fiorenza, 1998: 130 ss.).

No entanto, para que este passo hermenêutico não se torne um jogo infindável de interpretações, no qual todas as leituras têm validade, é preciso articular uma escala de valores e de visões, em ordem a julgar a indeterminação do texto e os seus significados. Fiorenza apresenta, então, o último passo, que consiste numa "hermenêutica da transformação radicalmente democrática" (cf. Fiorenza, idem). As interpretações devem ser avaliadas, para se saber se favorecem ou advogam valores kyriocêntricos ou libertadores. Estes critérios de avaliação e esta escala de valores não podem ser estáticos: o lugar da decisão e enunciação dos mesmos tem que ser a ekklesia of wo/men como realidade e como visão político-cultural e teológica: a primeira tarefa teológica de uma hermenêutica crítica libertadora consiste em

13 "For it is not possible to 'prove'methodologically that the bible advocates egalitarian democracy rather than kyriarchal monarchy since both forms of social organization are inscribed in the socio-symbolic universe of biblical writings. [...] The notions and beliefs we hold today inform how we read the texts of the past." 
fazer um escrutínio e em assinalar até que ponto determinados textos bíblicos e determinadas interpretações promovem um ethos kyriarcal e uma visão religiosa desumanizante, que legitima a injustiça e a opressão.

Kwok Pui-lan comenta este percurso do seguinte modo:

A interpretação feminista da Bíblia fez um longo percurso desde o dia em que as mulheres chinesas erradicaram das suas Bíblias as passagens paulinas que consideravam misóginas. Tornou-se um movimento global, à medida que mulheres com diferentes histórias e culturas desafiam as leituras patriarcais e articulam a sua fé e compreensão de Deus. Se a Bíblia foi o 'grande código' subjacente à civilização ocidental [...], as mulheres em todo o mundo reclamam, agora, o poder e a autoridade para re-contar, reescrever e reinterpretar este importante documento. (Pui-lan, 2005: 99) $)^{14}$

\section{Referências bibliográficas}

\section{Documentos oficiais da Igreja Católica}

João Paulo II, "Ad eos qui conventui consociationum 'Pro vita' ab omnibus nationibus interfuerunt coram admissos, in: AAS 84 (1992) 1061-1065.

João Paulo II, "Ad episcopos Civitatum Foederatarum Americae Septemtrionalis missus”, in: AAS 81 (1989) 1165.

João Paulo II, "Christifideles laici", n.50, in: AAS 81 (1989) 490.

João Paulo II, "Laborem Exercens", n.19, in: AAS 73 (1981) 627-628.

João Paulo II, "Mulieris dignitatem”, n.10, in: AAS 80 (1988) 1674-1677.

Paulo VI, "Octogesima Adveniens", n.13, in: AAS 63 (1971) 410.

Ratzinger, Joseph, "Apertura del Consistoro Straordinario", in: Osservatore Romano, 5/04/1991.

Sacra Congregatio Pro Doctrina Fidei, "Declaratio De abortu procurato", n. 15, in: AAS 66 (1974) 740.

\section{Textos da Patrística:}

Sto. Agostinho, De agone christiano XXII, 24.

Sto. Agostinho, De diversis quaestionibus octoginta tribus 11.

Sto. Agostinho, De fide et symbolo IV, 9.

\footnotetext{
14 "Feminist interpretation of the Bible has come a long way since the day when the Chinese woman excised from her Bible those Pauline passages that she considered misogynous. It has become a global movement, as women with different histories and cultures challenge patriarchal readings and articulate their faith and understanding of God. If the Bible has been the 'great code' undergirding Western civilization [...], women from all over the world are claiming the power and authority to retell, rewrite, and reinterpret this important document."
} 
Sto. Agostinho, De sermone Domini in monte XV, 41.

Sto. Agostinho, Gen ad litt. IX, 2, 3; Civ. Dei, IXX, 24; X, 20, 21; Civ. Dei XXII, 14.

Sto. Agostinho, Nupt. et concup. II, 4.12.

Sto. Agostinho, PL 38, col. 1108.

S. Tomás de Aquino, De ente et essentia II, 11-13; VI, 5.

S. Tomás de Aquino, Summa Theologica I, 75, 6, 1.4.6; I, 77, 5; I, 84, 7; I, 92, 1; I, 93 , 4 ad 1; I, 93, 6 ad 2; I, 99, 2.

\section{Outras referências}

Børresen, Kari-Elisabeth (1968), Subordination et équivalence. Nature et rôle de la femme d'après Augustin et Thomas d'Aquin. Oslo-Paris (Diss.): Norwegian University Press/Maison Mame.

Campbell, Karlyn Kohrs (1989), Man Cannot Speak for Her, I. New York: Greeenwood Press.

Carmo, Isabel; Amâncio, Lígia (2004), Vozes insubmissas. A bistória das mulberes e dos bomens que lutaram pela igualdade dos sexos quando era crime fazê-lo. Lisboa: Ed. Dom Quixote.

Chicago, Judy (1979), The Dinner Party: A Symbol of Our Heritage. New York: Anchor Press.

Dalarun, Jacques (1991), “Regards de clercs”, in George Duby; Michelle Perrot (dir.), Histoire des Femmes en Occident, 2: Moyen Age. Paris: Plon, 31-54.

Dube-Shomanah, Musa W. (1998), "Schrift, Feminismus und postkoloniale Kontext", in Concilium. Internationalte Zeitschrift für Theologie, 34/3, 278-287.

Fiorenza, Elisabeth Schüssler (1988a), Zu ibrem Gedächtnis ... Eine feministisch-theologische Rekonstruktion der christlichen Ursprünge. München-Mainz: Chr. Kaiser/ Gütersloher Verlag [trad. Christina Schaumberger].

Fiorenza, Elisabeth Schüssler (1988b), Brot statt Steine. Die Herausforderung einer feministischen Interpretation der Bibel. Freiburg-Schweiz: Edition Exodus [trad. Karel Hermans].

Fiorenza, Elisabeth Schüssler (1992), But She Said: Feminist Practices of Biblical Interpretation. Boston: Beacon Press.

Fiorenza, Elisabeth Schüssler (1994), "Gewalt gegen Frauen“, in Concilium. Internationale Zeitschrift für Theologie, 30/2, 95-107.

Fiorenza, Elisabeth Schüssler (1998), Sharing Her Word. Feminist Biblical Interpretation in Context. Boston, Beacon Press.

Goodwin, Mary E. (s.d.), "Racial Roots and Religion. An Interview with Howard Thurman”, in ChickenBones: A Journal for Literary \& Artistic African-American Themes. Extracto de entrevista original publicada em The Christian Century (9 Maio 1973), consultado em 21/07/2008, http://www.nathanielturner.com/racialrootsandreligion. htm. 
Grey, Mary (1997), “'Weint nicht über mich; weint über euch und eure Kinder!’ Religion und die Überwindung von Gewalt gegen Frauen”, in Concilium. Internationale Zeitschrift für Theologie, 33/4, 503-510.

Harding, Sandra (org.) (2004), The Feminist Standpoint Theory Reader: Intellectual and Political Controversies. Londres: Routledge.

Pui-lan, Kwok (2005), Postcolonial Imagination E Feminist Theology. Louisville: Westminster John Knox Press.

Toldy, Teresa Martinho (1998), Deus e a Palavra de Deus na teologia feminista. Lisboa: Ed. Paulinas. 